\title{
Configuración subjetiva del ejercicio de la dirección en directivos
}

\section{Subjective Composition of Direction in Managers Configuração subjetiva do exercício da direção em diretivos}

\author{
Daymarelis Maceo Vargas ${ }^{\star}$ \\ Diana Rosa Montero Tamayo*
}

Fecha de recibido: 16 de julio de 2016

Fecha de aprobado: 12 de diciembre de 2016

Doi:

Para citar: Maceo Vargas, D., \& Montero Tamayo, D. R. (2017). Configuración subjetiva del ejercicio de la dirección en directivos. Universidad \& Empresa, 19(33), 75-112. Doi:

\section{RESUMEN}

La configuración subjetiva del ejercicio de la dirección que poseen los directivos tiene un papel primordial en la conformación de la subjetividad organizacional y puede llegar a legitimarse, legalizándose con el paso del tiempo, por la cultura de la organización.

Por esta razón, el presente estudio, desarrollado con el objetivo de caracterizar la configuración subjetiva de esta actividad en directivos de la Gerencia ARTex, Sucursal Granma, aborda el tema desde la construcción de significados y sentidos por los sujetos investigados. Tal abordaje se llevó a cabo a partir de un estudio de casos múltiples y de la utilización del método fenomenológico. Las técnicas empleadas (análisis de documentos, observación no participante y entrevista en profundidad) permitieron develar, en tres sesiones de trabajo, la expresión de los indicadores de la configuración subjetiva identificados.

* Graduada de Psicología en la Universidad de Oriente (Santiago de Cuba). Profesora asistente, título obtenido en la Universidad de Granma (Cuba). Actualmente se desempeña como profesora del Departamento de Formación de Directivos. Correo electrónico: dmaceov@udg.co.cu

** Graduada de Psicología en la Universidad de Oriente (Santiago de Cuba). Profesora asistente, título obtenido en la Universidad de Granma (Cuba). Actualmente se desempeña como profesora del Departamento de Formación de Directivos. Correo electrónico: dmonterot@udg.co.cu. Código postal 85100 . 
Entre los resultados más relevantes se encontró que la configuración subjetiva del ejercicio de la dirección en estos directivos tiene como núcleo sentidos de orientación ganancial y del deber, apoyados en una representación amplia de la actividad y de vivencias de valencia mayormente negativas, que denotan una dinámica regresiva en la regulación de su comportamiento.

Palabras clave: configuración subjetiva, directivos, sentido subjetivo, organización.

\section{ABSTRACT}

The subjective composition of direction that managers have a main role in the conformation of organizational subjectivity and can be legitimated over time by the organization culture. Due to this, the present study, developed with the objective to characterize the subjective configuration of this activity in Managers of Gerencia ARTex, Granma branch office, talks about the construction of sense and meaning by the researched subjects. This viewpoint was done from a study of multiple cases and of the utilization of phenomenological method. The techniques used (data analysis, non-intrusive observation and deep interviews) showed, in three work sessions, the expression of the identified indicators of the subjective configuration. Among the most relevant results it was found that the subjective composition of direction in this managers has a core in senses of social and duty orientation, supported in a broad representation of the activity and valencia experiences mostly negatives, which show a regressive regulation of its behavior.

Keywords: subjective composition, managers, subjective sense, organization.

\section{RESUMO}

A configuração subjetiva do exercício da direção que possuem os diretivos, tem um rol primordial na configuração da subjetividade organizacional e pode chegar a se legitimar legalizando-se com o passo do tempo, pela cultura da organização.

Por esta razão o presente estudo, desenvolvido com o objetivo de caracterizar a configuração subjetiva desta atividade em diretivos da Gerência ARTex, Sucursal Granma; aborda o tema desde a construção de significados e sentidos pelos sujeitos investigados. Tal abordagem levou-se a cabo a partir de um estudo de casos múltiplos e a utilização do método fenomenológico. As técnicas empregadas (análise de documentos, observação não participante e entrevista em profundidade) permitiram revelar, em três sessões de trabalho, a expressão dos indicadores da configuração subjetiva identificados.

Entre os resultados mais relevantes encontrou-se que a configuração subjetiva do exercício da direção nestes diretivos tem como núcleo sentidos de orientação de rendimento e do dever, apoiado em uma representação ampla da atividade e de vivências de valência maiormente negativas; que denotam uma dinâmica regressiva na regulação de seu comportamento.

Palavras-chave: configuração subjetiva, diretivos, sentido subjetivo, organização. 


\section{INTRODUCCIÓN}

La complejidad de la situación internacional a raíz de la más reciente crisis económica ha tenido sus repercusiones particulares en todos los países del mundo. Cuba, país en vía de desarrollo, no ha quedado exenta de esto, y ante tal situación ha puesto en práctica un proceso de reformas en todos los ámbitos con el objetivo de estabilizarse económicamente para rebasar esta difícil etapa y garantizar con ello las conquistas sociales alcanzadas durante los años de Revolución. Sin dudas esto ha repercutido en todos los ámbitos de la sociedad, pero especialmente en las organizaciones laborales, sistemas complejos, abiertos, dinámicos y racionales, que la integran y con la que establecen una relación constante de interinfluencia, y dentro de las que el factor humano ocupa un papel fundamental.

Sucede que el hombre y/o la mujer pasa la mayor parte de su vida en las organizaciones, convirtiéndose ellas en un espacio de realización o frustración de necesidades y motivos; de construcción de significados y sentidos subjetivos que orientan y regulan el vínculo peculiar que establece con el entorno organizacional que le rodea, que es a su vez histórico, social y cultural.
Con esto se explica el hecho de que el sujeto ya es portador de un complejo sistema de configuraciones subjetivas que ha elaborado y actualizado a lo largo de su historia de vida, tanto a nivel individual como social, en los diferentes espacios con los que se ha relacionado, siendo capaz de integrarlo al complejo sistema de configuraciones subjetivas de la vida organizacional que al entrar a la organización ya funcionan. En esta interacción se adapta al medio formando parte y modificándolo para una mayor comprensión de la realidad objetiva y subjetiva existente. Este complejo proceso de funcionamiento y estructuración de 'complejidades' es lo que se conoce como subjetividad organizacional.

Siendo así, las organizaciones laborales, más que ser en esencia humanas, funcionan en sí como 'sujeto organizacional', integradas a su vez por una cultura organizacional en la que prevalece un sistema de significados, sentidos psicológicos, sentimientos y emociones que se manifiestan en los comportamientos y actitudes de su personal. Ahora bien, ¿sería posible organizar y guiar las organizaciones y los individuos que las integran hacia el logro de los objetivos, sin la presencia de un sistema como lo es la dirección? Esta debe ser capaz de 
lograr su plan, controlando los elementos que conduzcan a la organización a funcionar de acuerdo con los cambios que se dan en su entorno, a fin de mantener un equilibrio dinámico y asegurando la supervivencia de la entidad, sin dejar a un lado la satisfacción del factor humano. Por todos es conocido que, si la persona está satisfecha en su centro laboral y con la forma en que es dirigido, trabaja mejor, rinde más, aporta más ideas y se implica en el proyecto de empresa. Es por ello por lo que, a la hora de establecer objetivos de mejora, es vital partir de las personas y del valor que pueden aportar a la organización.

Por lo tanto, resulta primordial la satisfacción del trabajador con el ejercicio de la dirección de su organización para poder orientar y regular su actividad laboral a partir de la forma individual de internalizar los procesos que en ella suceden, al asignarles sentidos y significados que integran las configuraciones subjetivas; como parte de las vivencias, sentimientos y emociones que despierta la relación significativa que establece con ella.

En la Gerencia ARTex S.A., Sucursal Granma, encargada de crear, comercializar y promocionar bienes y servicios culturales que los distingan en el mercado por su valor para satisfacer las necesidades de los clientes y contribuir a financiar el desarrollo cultural del país, organización donde se desarrolla la presente investigación, se desarrolló un movimiento de los directivos por las insuficiencias que presentaba en el cumplimiento de los planes trazados. La nueva dirección de la organización permitió que en poco tiempo la sucursal cumpliera con sus indicadores técnico-económicos (llevaban dos años sin cumplirlos). Sin embargo, comenzaron a aparecer un conjunto de dificultades en el desarrollo de la actividad laboral asociadas al manejo y comprensión de las informaciones, sin dejar atrás el papel del rumor y el manejo de este. A lo cual se suma el tratamiento dado a los conflictos relacionados con su existencia y las soluciones propiciadas a otros vinculados con la actividad laboral. Situación que se complejiza con las expresiones de desmotivación laboral evidenciadas por parte de los trabajadores hacia la dirección, ya fuere por la falta de gestión en los procesos de capacitación, como por las relaciones con otros empleados en el trabajo en equipo. Elementos que marcan una falta de identificación de estos con la estrategia y su dirección reciente, aun cuando el resto de los directivos hayan tenido una relativa estabilidad como miembros del Consejo de Dirección. Tales datos fueron resultado 
de un estudio de clima laboral realizado por el Departamento de Imagen y Desarrollo, que tenía como objetivo el análisis de dicha problemática.

Evidentemente emerge un descontento asociado con el ejercicio de la dirección en la empresa y los procesos asociados a esta, por lo que se considera pertinente estudiar qué entienden los directivos de la institución por dirigir, cómo internalizan el ejercicio de su labor, cuáles son los sentidos que le confieren y qué papel desempeñan en la configuración subjetiva que les permiten orientar y regular su actuar en la empresa.

Entre los antecedentes teóricos y prácticos del estudio del tema se considera necesario resaltar la conceptualización proporcionada por Fernando González Rey (1997) con un valioso aporte teórico en su libro Epistemología cualitativa y subjetividad para la comprensión de la configuración subjetiva como categoría psicológica, así como del funcionamiento y conformación de la personalidad, sin dejar atrás una concepción de sujeto y metodología más coherente a la interpretación de la realidad de estos.

Sin embargo, su aplicación práctica es tratada más bien en otra investigación para optar por el título de Licenciado(a) en Psicología reali- zada en la Universidad de Oriente: Configuración subjetiva del ejercicio de la dirección en mujeres y hombres dirigentes (2002), de Raisa Rodríguezy Yezenia Ramayo, en la cual se aborda la temática desde un enfoque de género, buscando regularidades desde las características sociopsicológicas sobresalientes en mujeres y hombres que ejercen la dirección, así como posibles contradicciones en su accionar a partir de las concepciones genéricas. Por otro lado, se encuentran otros estudios, como Configuración subjetiva de la comunicación organizacional en la empresa azucarera América Libre, de Yoaris Bredy Sánchez (2008), y Configuración subjetiva de los valores organizacionales, de Irene Cordero (2009), en las que se aborda, desde una perspectiva cualitativa, la expresión de los indicadores de configuración subjetiva de los fenómenos estudiados en cada una. Enriqueciendo la interpretación y el acercamiento a la construcción de los sentidos de la realidad que hace el sujeto, están las tesis Acercamiento ala configuraciónsubjetiva de la capacitación de las auxiliares generales del hogar infantil, de Neudys Manzano Vidal (2010); Percepción de la dirección administrativa en la Dirección Municipal de Salud de San Luis, de Beatriz Reyes (2011); o Autonomía en mujeres directivas. Un estudio de casos múltiples, de Pilar González de la Rosa (2010). 
A partir de esta lógica de análisis, el ejercicio de la dirección emergió como un tema ampliamente estudiado desde diversas aristas, ya fuere teniendo en cuenta la visión que poseen los individuos de esta asociada a sus procesos cognitivos y afectivos, como su expresión en la regulación y autorregulación del comportamiento en la organización, tratando de obtenera través de ellos mejores niveles de eficiencia y eficacia, además de una mayor identificación de los trabajadores con ella. No obstante la configuración subjetiva del ejercicio de la dirección desde los propios sujetos que la ejercen, buscando las concepciones y sentidos que le confieren, incluida su repercusión en la toma de decisiones de la organización y su propio decursar, independientemente del género al que pertenezcan, no hasidoabordada desdetales estudios, lo que sería de gran beneficio dada la importancia que en la actualidad presenta para una mayor comprensión y acercamiento al factor humano, unido al futuro de las organizaciones laborales y de la nación. El presente estudio tiende a analizar y darle solución a las situaciones presentes en la sucursal a partir del estudio de la visión y configuración de tales contenidos a lo interno de cada sujeto de la investigación como parte de la relación bidireccional con el investigador proporcionando la posibilidad de la reflexión por ambas partes para que contribuyan de forma indirecta al crecimiento personológico, lo cual justifica su impacto social. Pudiendo, además, constituirse en basamento teórico para posteriores estudios relacionados con el tema y, a la vez, fuente de conocimiento para otros interesados en él.

El problema de investigación con el que se va a trabajar es: ¿cómo se configura subjetivamente el ejercicio de la dirección en los directivos de la Gerencia ARTex, Sucursal Granma?

Planteándose como objetivo general: Caracterizar la configuración subjetiva del ejercicio de la dirección en los directivos de la Gerencia ARTex, Sucursal Granma.

En su desarrollo se plantean los siguientes objetivos específicos:

1. Definir los indicadores diagnósticos de la configuración subjetiva del ejercicio de la dirección en los directivos de la Gerencia ARTex, Sucursal Granma.

2. Identificar el estado actual de la configuración subjetiva del ejercicio de la dirección de los sujetos investigados.

En el presente estudio se defiende la idea de que en la Gerencia ARTex, Sucursal Granma el ejercicio de la dirección se caracteriza por la 
existencia de amplias representaciones subjetivas, con prevalencia de motivos orientadores de sentido y de la actividad, vinculadas a vivencias afectivas con una mayor carga negativa y una dinámica regresiva, portadora además de diversos valores y sentimientos de alto contenido social.

\section{DESARROLLO}

\subsection{Aspectos teóricos}

\subsubsection{Hablando de configuración subjetiva en la personalidad}

El cómo se constituye la personalidad a lo largo de la historia de vida del sujeto y qué papel desempeña él en ella y los otros ha sido una gran interrogante que las diversas teorías y sistemas en la psicología han tratado de explicar durante el paso del tiempo. Desde el conductismo, que veía al hombre como un entramado de hábitos y aprendizajes, quitándole el papel activo que pudiera tener en la construcción de sí y su realidad, hasta el humanismo, que ponía toda su mirada en el ser y su autodesarrollo un tanto lejos del papel de la sociedad. Sin dejar atrás al psicoanálisis, que relacionaba dinámicamente a varias fuerzas al interno de la personalidad, marcando la relación peculiar del sujeto con los otros.
No obstante, fueron los psicólogos marxistas, adoptando una postura dialéctico-materialista, quienes contribuyeron con sus aportes a una comprensión de subjetividad, desde una visión ontológica y holística, en la que se integran elementos como afecto y cognición, lo social y lo individual, aun cuando su teoría, de valiosos aportes prácticos, no fuera capaz de extenderse al campo de la clínica como las otras, dejando desprovista a dicha ciencia de una terapia.

Tomando como base esta perspectiva, en la relación dialéctica que el individuo mantiene con el medio social se va conformando lo psíquico, lo subjetivo, lo psicológico, que denotan el carácter peculiar e individual de dicho vínculo, la relación con el medio social e interior del propio individuo y el papel activo que como sujeto portador de dicha subjetividad pueda desempeñar en este proceso. Así emerge el concepto de subjetividad como espacio de constitución de la psiquis humana e individual en los diversos momentos de relación del ser humano, con los diversos estados, procesos y sentidos subjetivos que sea capaz de conferirles. Por lo que se expresa tanto a nivel individual como social, como constituyente de esa vida social e individual, o sea, en los espacios donde el hombre sea capaz de asignar un sentido a la realidad objetiva. 
Diferenciándose una de la otra, al decir de González Rey (1997), no por su origen, sino por el escenario de su constitución.

La subjetividad social nos va mostrar cómo en cada espacio social, en la medida en que el hombre entra en relación con los otros, existe un proceso de subjetivación que no es simplemente su subjetividad individual, sino la del espacio que se está articulando (González, 1997). En este lugar la subjetividad individual toma una organización y funcionamiento singulares, ya que el sujeto tiene que producir espacios dentro de esos espacios sociales.

Desde este análisis, esta se desarrolla a lo largo de la vida del sujeto, de la concepción de su historia, resaltando en esta peculiaridad el carácter histórico y a la vez ontológico de su existencia. Está integrada y organizada en diversos subsistemas o configuraciones parciales con diversos grados de complejidad en perenne interrelación a medida que el individuo se inserta e interactúa con la sociedad (Fernández, 2002), en la cual tiene que constantemente adaptarse a los retos que le impone para desarrollarse. Desarrollo que no necesariamente se organiza de acuerdo con las necesidades actuales de organización y progreso de la subjetividad individual. De este modo, un elemen- to psicológico aislado no posee significación psicológica, sino en virtud del sistema en el cual se integre.

En este proceso de la subjetividad humana surge la categoría personalidad como una macrocategoría que representa el nivel superior de integración de sus contenidos y funciones (Domínguez, 2005). Es, por lo tanto, una realidad subjetiva, razón por la cual no tiene una existencia palpable amén de los comportamientos, conductas y estados del sujeto a partir de los cuales se expresa, interviniendo en su regulación como una compleja síntesis de lo cognitivo y lo afectivo en lo singular y social. Esto garantiza cierta estabilidad en su manifestación orientada hacia las principales esferas, donde predomina el eje de necesidades y motivaciones del sujeto, encaminadas al presente y con perspectiva al futuro.

Lo anterior denota el carácter relativamente estable de los contenidos y funciones de la personalidad. Sin embargo, en cada espacio de relación del individuo, en cada momento histórico, subjetivo (referido a la confluencia específica en tiempo y espacio de intereses, necesidades, motivaciones, estados, etc.) y concreto por el que transcurre, este es capaz de actualizar sus vivencias, los sentidos y significados, núcleos 
de las configuraciones inmersas en la personalidad, y así desarrollarse. Con lo cual se demarca el dinamismo e historicidad que la caracterizan, pues este complejo proceso de formación, desintegración y actualizaciones se lleva a cabo durante toda la vida del ser humano.

A esto hacía referencia Núñez de Villavicencio (2000, citado en Domínguez, Vargas y Fonseca, 2009) cuando afirmaba que la personalidad es un complejo sistema. Cuando un sujeto piensa, siente y actúa, responde con su personalidad como un todo. Sus elementos se hallan en unidad y fuerte interacción.

La personalidad permite a los individuos interactuar con el medio de una forma particular, a la vez que procesar e interiorizar la información que recibe de este de modo singular, convirtiéndola en sentidos psicológicos que dinamizan y regulan su comportamiento. Uno de los aspectos más característicos de la personalidad humana es su individualidad, por la cual se entiende un conjunto, único en su género, de particularidades psicológicas que hacen a cada individuo diferente de los demás. Es, por lo tanto, inconfundible en su individualidad.

Siendo de tal forma, en la relación sujeto-personalidad, el sujeto es el individuo en sus diferentes esferas de actuación, que organiza sus diversas vivencias y construye su identidad a partir de sus recursos personológicos, haciéndose referencia al individuo portador de una personalidad que tiene una capacidad volitivo-intencional, capaz de anticipar y proyectar su comportamiento (Fernández, 2002). Desde esta perspectiva, se diría mejor que es un sujeto con una tendencia activa ante las situaciones conflictivas de la vida diaria, en la búsqueda de su desarrollo y crecimiento personal. Un individuo, como sujeto social-individual (se ofrecen disculpas si parece una redundancia), que contribuye a la constitución y construcción de la subjetividad social y su propia subjetividad.

A medida que crece, en la interacción con el medio, internaliza los procesos y relaciones en las que participa y que en él se desarrollan de forma peculiar en dependencia de las formaciones, que, según su evolución biológica, pueda ir adquiriendo. Estas, a medida que avanza el proceso de crecimiento, se complejizan organizándose en complicadas configuraciones subjetivas, las cuales, teniendo como base los sentidos subjetivos, le permiten establecer una relación especial con el medio einterpretar la realidad objetiva, confiriéndole nuevos sentidos y significados 
propios, o simplemente actualizándolos, pudiendo externalizarlos y transformar su 'mundo', mediante la regulación y autorregulación del comportamiento.

Siendo así, la personalidad es un sistema de configuraciones psicológicas, estables en su funcionamiento pero no estáticas en su desarrollo, demarcando su carácter configuracional no solo en la organización de sus contenidos, sino también en su funcionamiento (Fernández, 2002). Dan cuenta al mismo tiempo de la organización de múltiples procesos que se desarrollan y articulan en la subjetividad individual a la que se refiere cuando categorías como ella (personalidad), configuración subjetiva y sentidos adquieren su expresión peculiar en el sujeto, resaltando aquí el papel trascendental de la formación de los sentidos subjetivos en la orientación y regulación del sujeto.

En este entramado juega un papel primordial la unidad de sus procesos cognitivos y afectivos subyacentes, a su vez, a la formación de los sentidos subjetivos que constituyen la célula básica y funcional de la personalidad. Siendo los procesos cognitivos aquellos que permiten el reflejo de la realidad que nos rodea, es decir, las percepciones, las representaciones, el pensamiento, la memoria, la atención; y los afectivos van a darnos la manera en que ese reflejo de la realidad nos afecta, cómo es vivenciada por cada ser humano, aportando en consecuencia, energía, activación e intensidad al comportamiento. Se expresan en sentimientos, emociones, intereses. Estos poseen expresión física y psíquica; además, son más primitivos que la cognición, constituyéndose en dicha unidad la base de la función reguladora de la personalidad.

Ahora bien, ¿qué son en esencia las configuraciones subjetivas a las que se hace alusión? Se hace imprescindible para su entendimiento recurrir a la teoría de Fernando González Rey (1997, Epistemología cualitativa y subjetividad), quien desde una postura dialéctico-materialista explicó la dinámica de los elementos que la componen y su funcionamiento en la regulación y autorregulación del comportamiento del individuo.

De esa forma expresa la constitución subjetiva de los distintos tipos de relaciones y actividades que caracterizan la vida social de la persona. Las configuraciones son categorías complejas, pluridimensionales, que representan la unidad dinámica sobre la que se definen los diferentes sentidos subjetivos de los eventos sociales vividos por el hombre.

$\mathrm{Su}$ carácter pluridimensional vendría en el sentido de la integración 
de variados elementos que se han convertido en estados portadores de un valor emocional estable, como en el caso de los estados emocionales. Dichos estados guardan su sentido subjetivo solo en la interrelación necesaria con otros estados constituidos en las configuraciones subjetivas a las que se integre.

Al decir de González Rey (2007, citado en Manzano Vidal, 2010, p. 19), la configuración subjetiva es "la organización de sentidos subjetivos que definen los procesos simbólicos y las emociones que se integran de forma inseparable en relación a [sic] las experiencias del sujeto dentro de los espacios simbólicos de la cultura".

La constitución de una configuración a nivel subjetivo no se expresa linealmente desde la lógica de que lo externo se impone desde fuera y define lo interno, sino, más bien, en su constitución, lo externo aparece definido dentro del propio proceso de externalización del mundo subjetivo del sujeto (González, 1997). Esto se refiere al hecho de que en el proceso de interacción con el medio, de actuar sobre y con él, el sujeto produce hechos y situaciones, que, en su novedad, aparecen desligados del o los procesos que le dieron partida, deviniendo en internos en la formación de los sentidos subjetivos.
Como parte de la constante interrelación dinámica con el medio histórico, social y cultural, el individuo, en medida de la satisfacción de sus necesidades y la representación sobre ello, va experimentando sentimientos y emociones que conforma en vivencias y ciertos estados dinámicos, los cuales al entrar en relación con otros adquieren determinado sentido subjetivo y conforman las configuraciones subjetivas. Solo en este espacio se define su verdadero sentido.

Dichas configuraciones se relacionan con otras presentes en la personalidad, en asociación con los estados dinámicos que la integran y sus sentidos subjetivos, actualizándose en constantes emociones y sentimientos que el sujeto vivencia en la relación con ese medio que además le exige la puesta en práctica de ellas para comprender la realidad. En este complejo proceso adquieren cierta estabilidad, denotando la personalidad. Desde este punto, superponiéndose, contraponiéndose y jerarquizándose en dependencia de su fuerza y sentido en la constitución subjetiva actual de la personalidad.

Dinamismo abordado por Lourdes Fernández al citar que "toda configuración subjetiva responde tanto a determinantes intrapsíquicos, que perennemente se están integrando y desintegrando en el contexto de 
configuraciones más relevantes, como al comportamiento del sujeto en el plano interactivo y subjetivo" (González, 1994, citado por Fernández, 2002, p. 49).

Desde esta lógica, al tratar la concepción de configuración subjetiva, pierde sentido la división entre la cognición y el afecto, pues estas constituyen una unidad funcional de notable validez para la comprensión de los fenómenos de naturaleza subjetiva. Al decir de González Rey (1997), en las configuraciones se constituye subjetivamente lo afectivo, pues en ellas las emociones diversas, asociadas a los estados dinámicos que la constituyen, se convierten en sentidos subjetivos estables del sujeto. Este es un proceso cuyo carácter dinámico no se define solo por componentes de naturaleza afectiva de la personalidad, sino por el propio sentido subjetivo de las operaciones y capacidades intelectuales organizadas, alrededor de las relaciones y actividades que se constituyen a nivel subjetivo en las diferentes configuraciones de la personalidad.

\subsubsection{Configuración subjetiva} del ejercicio de la dirección y sus indicadores

En la relación compleja y dinámica que establece el individuo con otros individuos y grupos humanos entran a jugar un papel esencial las organizaciones laborales, como un espacio de construcción de la subjetividad; así mismo, de asignación de significados y sentidos subjetivos. Siendo a su vez un área donde los diversos procesos y contenidos integrantes de la personalidad de dichos individuos se actualizan, desintegran e integran diferentes configuraciones subjetivas. Estas se desarrollan a lo largo de la historia del sujeto organizacional (individuo, grupo, organización) de forma singular, permitiendo la regulación $\mathrm{y}$ autorregulación de su comportamiento, así como de las relaciones que establezca con el entorno durante el proceso laboral que desarrolla, para cumplir la misión social encargada por la sociedad.

Aquí entra a jugar un rol preponderante la dirección, para orientar y guiar a las masas hacia el cumplimiento de la estrategia, mediatizada por los contenidos inmersos en las configuraciones subjetivas constituyentes de la personalidad de los directivos y que desempeñan un papel primordial en el desarrollo y efectividad de sus funciones, tanto para la organización como a nivel individual.

Dirigir es conducir al sujeto organizacional (con ello se entiende tanto al individuo como al grupo y la 
organización) hacia el logro eficiente y eficaz de los objetivos de dicha institución. Es el planeamiento, organización, dirección y control de las operaciones de la empresa, a fin de lograr los objetivos que esta persigue, según la opinión de Mary Parker Follett (1992, citada en Cordero, 2009). Por tal razón, se asume como una actividad consciente y especializada; por supuesto, sin querer inmortalizar la figura del directivo(a) en dicho puesto como un dios al que se le está vedada la posibilidad de cometer errores.

Desde un punto de vista formal, según Reyes (2011), es el proceso de trabajar con y a través de otras personas con el fin de conseguir objetivos para la organización de un modo eficaz. En esta línea lógica de pensamiento es importante destacar que los ocupantes del puesto forman parte de la organización, de ese sujeto organizacional, así como la forma de dirigir, los resultados y autoridad asignadas a su rol son parte de la cultura organizacional que legitima y legaliza el actuar en la empresa durante el decursar del tiempo.

Mirándolo desde esta perspectiva (del trabajo con y a través de las personas, y como actividad especializada), son vitales para el trabajo del directivo, entonces, las habilidades $\mathrm{y}$ destrezas que posea y manifieste en la relación con los demás trabajadores y los objetivos de la institución, con vistas al cumplimiento de la estrategia organizacional y la efectividad en el logro de esta.

De ahí que, para la realización de la caracterización de la configuración subjetiva del ejercicio de la dirección, se debe guiar el proceso de investigación hacia la significación, vivencias y sentidos subjetivos que adquiere dicho proceso para los directivos de la Gerencia ARTex, Sucursal Granma, analizados desde sus puestos laborales, en donde realizan dicha actividad y que se integra al entramado de sus configuraciones subjetivas, orientando y regulando el desempeño de su labor en la institución.

En tal sentido es que en este análisis se hace alusión al concepto de configuración subjetiva acuñado por González Rey (1997) y se enriquece en relación con los objetivos del estudio, por lo que se concibe como configuración subjetiva del ejercicio de la dirección al nivel de integración superior de los sentidos psicológicos que se constituyen en el sujeto organizacional en función de una actividad concreta: dirigir.

Respecto a lo cual los indicadores diagnósticos identificados de la categoría son: representación subjetiva, 
vivencia, motivación, sentido subjetivo y la dinámica configuracional, formando así una sólida base para el conocimiento y profundización de configuraciones subjetivas del ejercicio de la dirección.

- Representación subjetiva

Las representaciones subjetivas constituyen un proceso a través del cual el individuo comprende la realidad objetiva con la que se enfrenta diariamente; mediante ella, al decir de Zaldívar (1999), "el hombre ve al mundo y opera sobre él" (p. 167). Constituyen formas de organizar los contenidos de lo real, incluyendo esto tanto la realidad objetiva como subjetiva, siendo esta última sentida y percibida a su vez como realidad, por lo que en esa relación también se actúa sobre lo subjetivo como parte de tal realidad (sin temor a caer en un trabalenguas sin sentido).

En la opinión de Rubinstein (1982), la representación no es ninguna reproducción mecánica de la percepción, que se conserva en cualquier sitio como un elemento aislado e invariable para más tarde volver a aparecer en la superficie de la conciencia. Es una configuración dinámica variable, que cada vez se crea de nuevo bajo determinadas condiciones, reflejando la compleja vida de la personalidad.
De esto se entiende que recoge no solo los contenidos percibidos en el espectro de las relaciones del sujeto a partir de lo cual la realidad cobra vida para el individuo, sino que evidencia la complejidad de la organización y funcionamiento de la personalidad, expresando en este proceso simultáneamente los sentidos de su constitución subjetiva, en palabras de González Rey (1997).

Son expresiones de la acción activa del directivo (como sujeto organizacional) sobre su propio contenido psicológico, manifestándose como adecuación cognitiva o congruencia con los elementos de la realidad histórica y social en la cual se inserta como individualidad. Esto se logra en un complejo proceso de interrelación entre vivencias y reflexiones en diferentes momentos del desarrollo, sobre todo vinculadas al espacio de construcción de subjetividades que es la organización, facilitado porque dichas representaciones en la organización y funcionamiento de lo psicológico a lo interno del sujeto poseen una tendencia a convertirse en concepto o idea, es decir, en representar en detalle lo general, en el fenómeno lo esencial y en la imagen al concepto (Rubinstein, 1982).

La representación subjetiva, como proceso inmerso en la formación y funcionamiento de la configuración 
subjetiva del ejercicio de la dirección, es la reproducción consciente de imágenes y experiencias pasadas que constituyen la expresión y configuración de los sentidos subjetivos de los individuos. Resulta un proceso de construcción activa de la realidad objetiva sobre la actividad de dirección en la subjetividad del sujeto organizacional, razón por la cual a partir del análisis de estas categorías son factibles las transformaciones en las configuraciones subjetivas y las conductas que los llevan a esta.

Ellas le permiten a los directivos organizar los contenidos, pero a su vez se integran por los sentidos que de alguna manera estuvieron inmersos en su constitución, formando parte de las configuraciones subjetivas que giran en torno a su desempeño tanto pasado como presente y futuro. Tal elemento, a su vez, está supuesto a los cambios que necesariamente trae la relación con el medio, pues ellas abren de forma permanente nuevos espacios propiciadores de la producción de sentidos; mientras que, al mismo tiempo, se exponen en su quehacer diario en la institución (como en las reflexiones, discursos, decisiones, puntos de vista, etc.), regulando y autorregulando su comportamiento.
- Vivencias

La vivencia no es más que la relación afectiva del individuo con el medio, aquello que integra lo adquirido hasta el momento con lo externo. Constituye, refiere Vigotsky (1933), la unidad en que está representado lo experimentado por el sujeto y lo que este aporta al proceso (relación afectiva con el medio). Está asociada al proceso de desarrollo del individuo y al vínculo que sea capaz de establecer con el medio; al decir de González Rey y Mitjáns Martínez (1990, p. 128), son las "células psicológicas esenciales del proceso de desarrollo de la personalidad, sobre cuya base se aglutina un trabajo activo del sujeto para darle sentido a estos elementos en los marcos de su sistema personalizado actual, lo que lleva a que este proceso crezca y se amplíe".

Es una integración dinámica de procesos tanto cognitivos como afectivos, estableciendo dicha relación afectiva del individuo con el medio histórico-social y cultural. De ahí que Vigotsky (1933) le adjudicara una orientación biopsicosocial, de funcionamiento intermedio entre el desarrollo de la personalidad y el medio, con lo cual revela el significado de un momento dado de la realidad para el sujeto. Significado, 
sentido que tendría una estrecha relación con la satisfacción del sistema de necesidades y motivos de este, así como la actitud que adopte hacia el entorno y su propio desarrollo.

Tal relación se haría más complicada al abordarla desde la compleja integración y funcionamiento de los contenidos en la personalidad, en donde dichas necesidades y motivos se integran y operan desde formaciones, motivaciones, configuraciones subjetivas, las que se nutren del vínculo establecido con la realidad, definiendo y actualizando su sentido.

A partir de la vivencia, el individuo le adjudica a la información, los hechos y sucesos, la connotación, el sentido. En el acto de sentir, de vivenciar la información que se recibe, se conforman las configuraciones subjetivas, que incluyen la significación que tiene para el sujeto lo percibido y regulan el accionar particular de los dirigentes en la sucursal. De este análisis se deduce que es el ser humano quien denota el carácter a la situación, a partir de cómo la vivencia, de cómo le asigna un sentido. Ya lo afirmaba Vigotsky (s. f., citado en Cordero, 2009, p. 19) al expresar que "lo esencial no es la situación sino el modo como vive el individuo la situación".

Razón por la que la unidad e interinfluencia entre el entorno y las ca- racterísticas de la personalidad del sujeto es dialéctica. Constantemente el directivo valora las vivencias experimentadas a partir de un balance afectivo-emocional, teniendo en cuenta el sentido que le otorga a la labor que realiza. De la misma evaluación que realiza el sujeto de la posibilidad de satisfacer sus necesidades y motivos en la sucursal, así como de la forma en que se satisfacen (ya sean en la mayor o menor medida en comparación con sus proyectos), el dirigente experimenta afectos, emociones y sentimientos matizados por la fuerza en el movimiento subjetivo interno que le imbrican los sentidos asociados a tal satisfacción. A raíz de lo cual vivencia dichas situaciones con una valencia positiva o negativa.

Esto permite que pueda asociar ciertos contenidos en determinadas situaciones a vivencias y estados de bienestar o displacer y desde aquí integrar sus configuraciones subjetivas, además de regular su comportamiento en la organización. Una cosa sí es cierta, aun cuando puedan mantener cierta estabilidad, constantemente el dirigente está vivenciando su relación con el entorno organizacional, actualizándola y modificándola.

Otro elemento asociado a la comprensión de las vivencias en el entramado de las configuraciones sub- 
jetivas del ejercicio de la dirección es su funcionamiento consciente o no, dada su relación con los sentidos y significados subyacentes de la relación con el medio, existiendo un complejo vínculo entre la vivencia y el reconocimiento del objeto con el que se relaciona. Ya explicaba Rubinstein (1982) que "el devenir consciente de la vivencia no es siempre y necesariamente su confinamiento al mundo interno, sino su puesta-enrelación con el mundo interior, objetivo" (p. 23), integrándose al análisis y reflexión que ejerce sobre sus contenidos subjetivos como parte de su papel activo en la regulación y desarrollo personal. Agregando luego que una vivencia inconsciente es "una vivencia en la cual no nos damos cuenta del objeto que la produce; la vivencia misma no es inconsciente sino su relación con aquello a lo que se refiere" (p. 23).

Desde esta lógica emerge la relación estrecha que existe entre los procesos cognitivos y afectivos y su integración en la personalidad del individuo, para permitir la regulación por parte de este de su comportamiento, sin olvidar el vínculo constante con el medio, que demanda cambios y transformaciones en los contenidos de dicho individuo para su adaptación y desarrollo en la vida, así como su capacidad para participar y regular los contenidos que integran su personalidad, in- cluido su funcionamiento; en todo lo cual la vivencia: su contenido, valencia y el cómo el directivo la interprete e integre al entramado de sus configuraciones subjetivas alrededor de su función y lugar en la empresa, desempeña un papel esencial.

\section{- Motivación}

Abordados elementos integradores de las configuraciones subjetivas, como las representaciones y las vivencias, desde lo que el directivo conceptualiza y comprende de la realidad y de sí, hasta la intervención en ello del cómo siente esa realidad (en relación con sus necesidades y motivos) y la incorpora al funcionamiento de su personalidad, para regular su comportamiento y adaptarse al medio. Proceso de regulación y autorregulación en el cual la motivación, como fuerza impulsora de la actividad humana, entra a jugar un papel esencial, siendo capaz de constituirse en proceso imprescindible en la esfera laboral donde el ser humano adulto se desempeña y ocupa la mayor parte de su tiempo diario, en busca de la satisfacción de necesidades de diversa índole, tanto materiales como de autorrealización.

Al decir de González Rey (1983, citado en Riquenes, 2009), la motivación es un proceso psicológico que regula y moviliza el comportamiento 
humano. En dependencia de ello va a ser la intensidad y la fuerza con que el individuo moviliza su personalidad para el logro de ciertos propósitos. Determina su orientación y está directamente asociada al surgimiento de motivos determinantes, suficientemente estables, que ocupan un lugar importante en la jerarquía de esta orientación. Ella está definida por la combinación de factores internos y externos.

Lamotivación se encuentra en elcentro de la actividad. Es un reflejo de la realidad exterior, la realidad objetiva, y es una expresión de la personalidad, participando en ella tanto los procesos afectivos (emociones, sentimientos, estados de ánimo) como losprocesos cognitivos(sensaciones, percepciones, pensamientos, memoria) y tendencias, al decir de González Serra (1995) cuando se refería a procesos voluntarios e impulsivos. Además, constituye una expresión de las propiedades y del estado de la personalidad (carácter, aptitudes y temperamento), la cual posee su fuente principal en las necesidades humanas, siendo una compleja integración de procesos psíquicos que implican, a su vez, la actividad nerviosa superior.

Tiene su expresión en los motivos, los cuales, según Calviño (2005, citado en Domínguez et al., 2009), "son la representación subjetiva o mental del objeto, lugar o cosa que satisface una necesidad" (p. 19). O sea que la motivación es ese impulso para la acción, para llegar a alcanzar dicho objeto, lugar o cosa que está asociado a la satisfacción de cierta necesidad. Eso sí, dichos motivos se diferencian entre sí por la necesidad a la que responden, además de la compleja integración que forman, pues pueden estar asociados a varias necesidades, como varios motivos pueden ser el 'objeto' de satisfacción de una necesidad, integrándose en las formas complejas de la actividad y funcionando simultáneamente, lo cual le permite conformar un sistema ramificado de motivación de las actividades y actuaciones del hombre. Sin olvidar que la diferencia también puede venir por su amplitud, limitación o el contenido concreto de la actividad en la que se manifiesta.

En dichos términos, la necesidad aparece como un sentimiento o estado de ánimo, que expresa la ausencia de algo, acompañada de mecanismos que estimulan a la persona a vencer esa ausencia y a satisfacer esas necesidades. La motivación, en relación con esta, regula, entonces, la dirección (objeto-meta) hacia la cual va dirigida la actividad y la intensidad o activación del comportamiento, $\mathrm{y}$, por lo tanto, se manifiesta como 
actividad motivada en interrelación con sus objetos y estímulos, teniendo como base a los motivos.

Cuando el individuo se siente motivado por la actividad que realiza y capacitado para ella, puede ser realmente productivo, pues dirige y focaliza mejor el esfuerzo hacia las metas deseadas, que estarán en estrecha relación con la consecución efectiva y desarrollo de la actividad en cuestión. Al adaptarlo al ámbito organizacional, en tanto motivación por la profesión, este proceso se relaciona estrechamente con la amplitud del conocimiento que posea el sujeto sobre el contenido de la actividad laboral, su objeto y utilidad; así mismo, de la relación que emerge con las demandas a su persona y los recursos con los que cuenta tanto presentes como posibles por desarrollar para desempeñarse y adaptarse a esta.

A lo cual se integran las vivencias, emociones y sentimientos desarrollados en el ejercicio de su labor, en relación con la satisfacción de sus necesidades e intereses personales y profesionales, que de alguna manera denoten la implicación o el vínculo afectivo-emocional con esta. También, de la habilidad que posea para elaborar y evaluar conscientemente estos contenidos. Planificar y orientar, además, los cambios y recursos necesarios para desarrollarse a través de ella o con ella. Por supuesto, en una dimensión temporal, en la que el carácter de la participación del sujeto en la regulación y autorregulación de su comportamiento de manera consciente y voluntaria le permitirá trascender de lo inmediato a lo mediato.

Los motivos, en resumen, son las formas en que la personalidad asume, procesa y elabora sus diferentes necesidades, lo que implica generalmente un nivel de reflexión y mediatización. Esto no quiere decir que este proceso sea $100 \%$ consciente. Proceso (valga la redundancia) que subyace e interactúa con los sentidos subjetivos, y que será el espacio que precisará las diferentes actividades y formas de relación en que dichos motivos se expresan. Tienen, además, un contenido objetivo, por lo que le imprimen dirección y fuerza a la personalidad, es decir, la orientan hacia la satisfacción de sus necesidades, que pueden ir desde las más elementales (según la pirámide de Maslow), las fisiológicas o de afecto y filiación, hasta las de superación y autorrealización.

Desde esta lógica, los motivos tienden a poseer, como los demás contenidos de la personalidad, un funcionamiento estable. 
Bien lo decía Rubinstein (1982), "los motivos portadores de elevada carga emocional en la estructuración de las formaciones de ellos derivadas se convierten en nudos vitales de la personalidad, y se expresa tanto en el plano de la conducta como de la subjetividad" (p. 239).

Los motivos estables forman en la personalidad una estructura jerárquica; unos se hacen dominantes, pues son más importantes para el individuo, por lo que se resisten más a quedar insatisfechos. La orientación de la personalidad es el resultado de la presencia de los motivos estables que dominan la conducta y a su vez subordinan a otros motivos. Son estos a los que se hace referencia fundamentalmente cuando se habla de configuración subjetiva, por poseer un mayor nivel de complejidad en la estructuración y funcionamiento de la personalidad. Los que integran en un mismo sistema diferentes elementos dinámicos procedentes de las diversas necesidades del individuo.

Relacionado con la motivación profesional, los motivos pueden ser extrínsecos o intrínsecos a la actividad profesional; el sujeto hace como suyo y determinante en su desarrollo no solo una profesión, sino también a sí mismo, por medio de una conducta activa, pues en la motivación intrínseca los motivos profe- sionales reflejan en el sujeto acciones que adquieren sentido al querer hacerlas y por las vivencias al ejecutarlas, mientras que la motivación extrínseca requiere compensaciones a cambio de la tarea por realizar o realizada, dependiendo directamente de un estímulo externo que mueva la conducta (Delgado, 2011).

Existen diferentes tipos de motivos, atendiendo a su funcionamiento en la jerarquía motivacional, que pueden estar presentes en la personalidad de los directivos de la sucursal $\mathrm{y}$ desde donde funcionan; según González Rey (1989), estos son:

- Motivos de carácter objetal: encarnan una necesidad y devienen motivos de comportamiento en este proceso. Esto se determina por el carácter inmediato de su gratificación, que se da para el objeto mismo.

- Motivos presentes ante condiciones actuantes: solo se activan ante determinadas condiciones que los estimulan, por ejemplo, de tipo valorativo, estético, organizativo. No disponen de suficiente fuerza para manifestarse de manera autónoma.

- Motivos orientadores de la actividad y de las relaciones del hombre: son los motivos que regulan de manera espontánea el comportamiento del sujeto, 
participan de él en las distintas relacionesy actividades en que se implica la personalidad. Pueden ser estables o no. Su expresión se automatiza y no exige la participación activa de la conciencia, predominan las vivencias positivas en el proceso de su realización.

- Motivosorientadoresdel sentido: por regla general, la necesidad esencial de estos motivos coinciden por su contenido, lo que determina que en el proceso de su realización por la personalidad predomine la vivencia positiva. Regulan el comportamiento básicamente en su expresión presente, sugieren reflexiones al sujeto acerca del sentido de la vida.

- Tendencia orientadora de la personalidad: nivel superior de la jerarquía motivacional, orientado hacia los objetivos sociales en la vida; formada por los motivos que realmente orientan a la personalidad hacia sus objetivos esenciales en la vida, lo que presupone una estrecha relación de la fuerza dinámica de estos motivos con la elaboración consciente por los sujetos de sus contenidos.

Sobre la base de este proceso, los motivos adquieren un sentido consciente personal para el sujeto, todo lo cual propicia la organización de complejas formaciones motivacionales, como ideales y autovaloración, conduciendo a la aparición de la autorregulación.

"Los diversos motivos y necesidades se aglutinan alrededor de una tendencia orientadora, la cual le confiere el sentido psicológico a las formaciones motivacionales que se integran. Estas últimas constituyen configuraciones subjetivas de la personalidad, y este es el modo de organización y de expresión de las tendencias orientadoras en las esferas concretas de la vida, lo cual se produce como parte del complejo sistema regulador" (González, 1997, p. 239).

Entre sus características se encuentran:

- La necesidad fundamental que está en la base del motivo coincide con su contenido y con la forma de relación en que este se expresa.

- La necesidad se expresa mediante una compleja elaboración consciente del sujeto acerca de su contenido.

- Su expresión plena se logra sobre todo en las reflexiones, juicios, valoraciones y puntos de vista del directivo que adquieren una fuerte carga emocional y participan de manera activa en la regulación del comportamiento. 
- Su expresión fundamental sobrepasa el momento presente, proyectándose en una gratificación mediata, bien estructurada.

Para que la motivación hacia la profesión, por ejemplo, se convierta en una tendencia orientadora de la personalidad (según González Rey, 1983): el sujeto debe ser capaz de estructurar sus motivos profesionales esenciales en las dimensiones de su vida presente y futura, basadas en fundamentos y elaboraciones conscientes de sus propósitos en esta esfera, desde una postura autorreflexiva y voluntaria. Proceso que ocurre en el plano subjetivo, lo cual favorece el desarrollo de sí mismo como persona, de la profesión, la institución y la sociedad en que vive.

- Sentido subjetivo

Al conceptualizar las configuraciones subjetivas se hacía referencia al papel central que desempeñan los sentidos subjetivos como elementos dinamizadores de los estados emocionales que las conforman. Ahora, ¿qué entender por esta categoría?

Los sentidos subjetivos se constituyen a lo largo de la vida del sujeto de una creciente integración cada vez más compleja de procesos afectivos (emociones, estados de ánimos, sentimientos) y cognitivos (percepcio- nes, representaciones, pensamiento). Emerge como resultado de la mediatización del sujeto portador de una personalidad, aun cuando el sentido de esta acción constructiva no va a depender de su intención.

Los sentidos psicológicos podríamos entenderlos, en una concepción inicial, como unidades psicológicas primarias en forma de contenidos parciales, estables, definidas psicológicamente, al decir de González Rey (1997).

Es por ello por lo que una de las categorías importantes del enfoque configuracional es el sentido subjetivo, el cual se constituye a partir de la unión de su especificidad y la historia irrepetible de la propia personalidad individual donde se configurará. Con esto se brinda especial atención al papel de la experiencia, como parte de la historia personal, en la vida del ser humano y en la formación del sentido subjetivo, explicándose por las formas en que se integren, según González Rey (1997), los sistemas actuales de vida social del sujeto con las configuraciones subjetivas anteriores de su experiencia individual, combinación a la que Vigotsky denominó situación social del desarrollo.

El sentido subjetivo es el significado que tienen para cada ser humano 
las diversas y complejas relaciones de la realidad. Se va formando a lo largo de todo el desarrollo de la persona y de las influencias sociohistóricas que recibe y mediatiza, a partir de una creciente integración de procesos afectivos y cognitivos entretejiéndose en el complejo sistema de la personalidad. Con respecto a esto atribuye un sentido a su relación con el medio, que va a ser única e irrepetible, matizando el dinamismo de su personalidad y su función reguladora y autorreguladora.

Su importancia vital para el entendimiento de la subjetividad era bien explicada por Leontiev (1983, citado en Blanco, s. f.) al expresar que era indiferente que el sujeto concientice o no los motivos, que diera fe o no de estos y de su existencia en forma de vivencias de interés, deseo o gusto; su función, tomada desde el punto de vista de la conciencia, consiste en 'valorar' en cierto sentido la significación vital que tienen para el sujeto las circunstancias objetivas, y sus acciones ante estas circunstancias le confieren un sentido personal que no coincide directamente con la comprensión de su significación objetiva.

Desde esta óptica de análisis, se asume entonces que cada fenómeno social tiene su significado, dado por la práctica social y cultural (el significado), y su significado subjetivo, producto de la vida del sujeto, así como de las reflexiones y valoraciones personalizadas de su situación sociohistórica (el sentido). El sentido de un hecho para un sujeto no siempre coincide con su significado social, depende de su configuración subjetiva en el sujeto portador de la personalidad, además del vínculo con sus necesidades e intereses puestos en relación en la situación específica formadora del sentido.

Calviño (2005, citado en Domínguez et al.) añade que el sentido como expresión de la unidad entro lo cognitivo y lo afectivo deviene a su vez en unidad fundamental de la conciencia y que esta categoría permite descubrir el movimiento directo de las necesidades e impulsos del hombre a la dirección conocida de su pensamiento.

Aparece de esa forma, no ya como una formación relativa a un producto de la vida individual de un sujeto concreto, sino como el resultado de la interacción del conjunto de sus relaciones sociales en las que se conforman con un sentido que trasciende los límites de lo personal individual. En la estructuración de la subjetividad son diversos, con disímiles combinaciones, formas de organización y complejidad.

Los sentidos subjetivos se expresan a través del sistema de sentimientos 
(emociones que se estabilizan), motivos y valores que el sujeto experimenta en los diferentes procesos y momentos de su existencia, lo cual indica el grado de integración, de su implicación y compromiso con dichos procesos y momentos. Que en palabras de González Rey (1997) sería más bien que el sentido subjetivo de un motivo, o una configuración de la personalidad, se definirá por el tipo de emoción que caracteriza su expresión en diferentes actividades del sujeto, del estado dinámico; por lo tanto, el sentido está comprometido simultáneamente con la constitución subjetiva del ser humano en acción, de su expresión en la actividad concreta, en su comportamiento.

Su interrelación es compleja teniendo en cuenta los elementos abordados dentro de las configuraciones subjetivas de la personalidad. Así, la especificidad de las propias respuestas emocionales que caracterizan las diferentes formas de relación de la persona a partir de la satisfacción de sus necesidades se integra a la constitución subjetiva de los motivos en la personalidad (se refiere a los que denotan por su valencia en la subjetividad del individuo cierta estabilidad), dentro de los cuales pasan a constituir estados dinámicos de uno o varios sentidos subjetivos.

El ejercicio de la dirección toma diversos sentidos de acuerdo con los significados que tienen para el individuo en la organización, razón por la cual son muy variados en su expresión y funcionamiento según el contexto en el que aparecen y las particularidades de la personalidad en que se configuran. Siendo referidos particularmente en cada investigación, como en el caso de los sentidos subjetivos de la capacitación referenciados por Manzano Vidal (2010):

- Sentido de crecimiento y desarrollo humano: expresa cómo en la entidad su contenido está en función del desarrollo del sujeto y cómo se evidencia la existencia de una interrelación cognitivoafectiva respecto al fenómeno de la dirección, constituyéndose para dicho sujeto motivo orientador de su comportamiento hacia el logro de objetivos importantes en el desarrollo profesional, social y personal en su organización. Está vinculado a valores y normas de la organización laboral.

Predominan las necesidades de autoestima, autorrealización, autodeterminación, etc., el ser humano es el centro de referencia de los sentidos. Además, los motivos se orientan al desarrollo personal y la retribución sociopsicológica (prestigio, reconocimiento, consideración, la valoración positiva por parte de los otros, estatus). 
- Sentido del deber: expresa cómo el directivo no personaliza la importancia del fenómeno para su desarrollo; este no adquiere un sentido individual significativo para su persona, por lo que su actitud va a estar mediatizada fundamentalmente por la presión de los agentes externos y los valores que este posee de los deberes que tiene como trabajador.

- Sentido de evasión o rechazo: conjunto de sentidos que expresan un bajo nivel de desarrollo e integración de la implicación y el compromiso del sujeto en torno a una actividad o fenómeno, o sea, no tiene ninguna carga afectiva y cognoscitiva que movilice su actitud respecto a este. El sujeto lo rechaza porque no forma parte de sus necesidades e intereses y no resulta importante para su actividad personal.

- Sentido instrumental o ganancial: expresa la necesidad personalque da respuesta a la obtención de determinados objetivos, portadores de alguna ganancia para la organización y para sí mismo.

- Sentido social: expresa la necesidad relacionada con el cumplimiento de la misión organizacional y sus objetivos, responde más directamente a los sentidos que adquieren para los trabajadores los resultados de su desempeño en términos sociales.
En la relación del sujeto con su contexto organizacional inmediato, los aspectos característicos de este último van adquiriendo sentido para él, siendo partícipe a su vez en la producción de sentidos (ya sea con una tendencia pasiva o activa en su comportamiento) y con ello su implicación e identificación con la estrategia organizacional y los resultados de la sucursal.

El sentido subjetivo, como piedra angular en la existencia y funcionamiento de las configuraciones subjetivas en torno al ejercicio de la dirección de los directivos de la empresa, es una postura de ellos de individualidad ante la realidad, como sujetos portadores de una personalidad. Es un sentimiento estable, un vínculo afectivo emocional, una actitud que implica la tendencia del sujeto a descubrir peculiaridades y esencias del objeto con el cual establece una relación subjetiva de carácter cognoscitiva-afectiva.

- Dinámica de la configuración subjetiva

Alrededor de cada motivo se integra el potencial dinámico de la personalidad, a través de las necesidades diversas constituidas a lo largo de la vida del sujeto. Estas necesidades constituyen un factor dinámico susceptible a nuevas y simultáneas 
formas de integración dentro de la personalidad. Integración que se relaciona con determinadas emociones y estados dinámicos, denotando el sentido de su integración en una configuración subjetiva.

Dicho potencial dinámico hace alusión al progreso en el desarrollo del movimiento del individuo o no. Según Calviño (2000), las tendencias dinámicas en la personalidad marcan los modos basales en que se retienen las experiencias con los objetos y sujetos, asociados a la realización de esas carencias y deseos. Ellas fijan intentos, a veces desesperados, irracionales, de dar cobertura a las exigencias que suponen las necesidades. Otras veces encuentran formas más plenas de satisfacción, más equilibradas en relación con las exigencias internas y externas.

Para abordar la dinámica de la configuración subjetiva del ejercicio de la dirección, sería importante partir de la concepción de dinámica como fenómeno que denota movimiento, fuerza, que puede ir a su vez en pos del avance o repliegue. Relacionado con este tema, Calviño (2002) muestra tres enfoques para su comprensión en relación con su tratamiento en la psicología:

1. El primero utiliza la palabra dinámica como opuesta a estática y significa el estudio de la conducta como proceso en movimiento, en sus cambios y transformaciones.

2. El segundo reserva el término para la reducción de todo fenómeno a las fuerzas que lo originan y condicionan. No solo examina un fenómeno como tal, sino también las fuerzas que lo producen. No estudia actos aislados, sino el fenómeno en términos de proceso, de progresión o regresión.

3. El tercero se refiere a toda investigación psicológica que centra su estudio en las motivaciones de la conducta.

Se asume, entonces, como el vínculo dialéctico del individuo con la realidad, matizado por su constante adaptación, en el cual debe realizar un interjuego de sus necesidades e intereses para su satisfacción, emergiendo en este proceso contradicciones, conflictos y problemas, los cuales, puestos en relación con el contenido subjetivo del individuo, pueden desintegrar lo ya analizado y representado o modificarlo, ya sea en un sentido de progreso o retroceso. Bien lo explicaba Vigotsky (1933, citado en Domínguez, 2005) en la Ley fundamental de la dinámica de las edades, en la cual indica que el desarrollo psicológico específicamente humano (aun cuando haya dedicado sus estudios fundamental- 
mente a la etapa infantil) debe ser entendido como proceso que conduce al sujeto a alcanzar, paulatinamente, pero también a 'saltos', nuevos niveles de regulación y autorregulación de su comportamiento; incluso cuando esto trae aparejado la contradicción entre lo ya lo logrado y lo nuevo por alcanzar, pudiendo uno negar lo otro.

Precisamente en la imposibilidad de satisfacer plenamente una necesidad emergen las contradicciones, conflictos, problemas, a lo cual se refería González Rey (1997) al expresar que "la unidad de cada configuración subjetiva viene dada por su capacidad para integrar elementos dinámicos contradictorios" (p. 16).

Ahora bien, existe una distinción entre ellos, analizados desde la psicología de las organizaciones por Bleger (1964, citado en Fernández, s. f.), entre otros teóricos. En función de ello la dificultad se puede abordar como dilema o contradicción (cuando se plantea en términos paradójicos que clausuran todo intento de solución); conflicto (el planteo se realiza en términos de dos posturas contrapuestas, donde de alguna manera se ha tomado conciencia de su existencia, no así de su solución); o problema (el planteo se hace a modo de interrogante que abarca la dificultad y su posible significación).
Se explicaría con esta categoría la integración de los diversos contenidos en la subjetividad y su funcionamiento en la personalidad del sujeto que constantemente se nutre y actualiza sus contenidos en el vínculo con el medio.

Puede existir una tendencia del individuo a asumir riesgos y solucionar conflictos, de acuerdo con la existencia de mecanismos capaces de reconocer las contradicciones y las tensiones, plantearlas como problemas y proponer soluciones. De ser así estaríamos en presencia de un individuo con una tendencia al desarrollo personal, de seguridad en la toma de decisiones dirigidas hacia lo factible.

Mientras que, en el lado opuesto, estaríamos en presencia de un sujeto, objeto de la situación, transversalizando su comportamiento por estereotipias, enajenación y uso de dificultades como elementos de justificación. Por supuesto, sin olvidar en este análisis la emergencia de contingencias que le brindan cierta flexibilidad. Elemento al cual se refería Maslow (1968, citado en Calviño, 2000) al afirmar que existen dos grupos de fuerzas que arrastran al individuo, además de las presiones hacia adelante, hacia la salud, también hay presiones hacia atrás, regresivas y de temor, las cuales 
llevan a la enfermedad y al debilitamiento.

Razón por la cual podríamos hablar de una modalidad regresiva y progresiva de la dinámica, presentando ciertas características, según Fernández (s. f.).

La modalidad progresiva de la dinámica se caracteriza por el hecho de que el sujeto (individual y social) posea las siguientes características:

- Capacidad para identificar y controlar los aspectos irracionales, las contradicciones y las tensiones de funcionamiento.

- Capacidad para elaborar y planear proyectos encaminados a la solución de problemas.

- Autonomía respecto a las instituciones externas y la posibilidad de cuestionar y realizar modificaciones a lo instituido.

- La pertenencia en función de proyecto y una orientación hacia el futuro.

- Compromiso intenso y voluntad de los miembros para la curiosidad, el interés, la exploración, la creatividad para realizar los cambios necesarios en el sentido progresivo.

La modalidad regresiva de la dinámica se caracteriza por el hecho de que el sujeto (individual y social) presente las siguientes características:
- Pérdida de la capacidad para evaluar situaciones, discriminar necesidades y problemas y orientar acciones exploratorias de solución.

- Predominio del prejuicio sobre el juicio basado en el análisis de los hechos.

- Incremento de conductas impulsivas.

Muchas veces la incomodidad y el incremento de la angustia que se producen conllevan la idealización de algún estado pasado al que se trata de regresar y que se evoca con profunda nostalgia. La comprensión de la dinámica supone una visión holística del ser humano en la que se integran contradicciones, conflictos, motivaciones, transformaciones, etc. Esta dinámica de la configuración subjetiva guarda relación con los siguientes indicadores de análisis (López, 2011):

- Indicadores de contenido: incluye las necesidades y motivos, sentimientos, valores e intereses.

- Indicadores subjetivos: integra el nivel de conciencia, de autoconciencia, la voluntad y sentido subjetivo.

- Indicadores de proceso: implica criterios compartidos o comunes, la aceptación y la existencia de contradicciones, posibilidad de aparición, aceptación y gestión 
de conflictos, su estudio y la elaboración de estrategias para propiciar cambios hacia niveles cualitativamente superiores.

Las configuraciones subjetivas expresan cierta movilidad. El sujeto no es capaz de modificarlas de manera brusca, sino mediante un proceso donde se transforman paulatinamente las representaciones, creencias y vivencias que posibilitan su enfrentamiento a representaciones ya conformadas. Tal proceso de construcción y deconstrucción constituye en sí la dinámica de constitución de las configuraciones subjetivas del ejercicio de la dirección.

\subsection{Aspectos metodológicos \\ 1.2.1. Metodología y método empleados}

La categoría configuración subjetiva es compleja en su formación y expresión, razón por la cual dicha investigación se basó en la metodología de corte cualitativo en función de comprender la realidad, los sentidos y significados que sobre ella se configuran y en ese proceso develarlos, conjuntamente con el sujeto en una relación de horizontalidad, respetando el carácter activo de este.

La utilización de esta metodología responde a las características de la información usada en la presente investigación, pues esta presenta un carácter subjetivo, mediatizada por el aprendizaje de lo histórico-social y el papel activo del sujeto, dando lugar a la formación y desarrollo de su personalidad. No se trata de buscar la causa del problema, sino de profundizar en los significados otorgados por los sujetos, teniendo en cuenta la cultura, las tradiciones y los conceptos construidos en su vida cotidiana (Bisquerra, 1989; Rodríguez, Gil y García, 1996). La metodología cualitativa desde un enfoque holístico trata de captar la realidad como un todo unificado, en el espacio de significación de los directivos que no puede fragmentarse en variables dependientes e independientes. Su fin es la descripción, análisis, interpretación y comprensión del ejercicio de la dirección desde la perspectiva del discurso de los sujetos. A partir de este punto de vista, permite adentrarse en la comprensión de los significados y sentidos construidos por los directivos en torno a la actividad que desempeñan.

Esto lo posibilita el tratamiento de la problemática desde el método fenomenológico. Este es esencial para la concepción de la metodología cualitativa que se plantea, pues la conducta humana, lo que el sujeto dice y hace, es producto del modo 
en que define, siente y vive su mundo. De manera que este método intenta ver las cosas desde el punto de vista de esas personas, sobre la base de los significados y sentidos subjetivos que los fenómenos sociales tienen para ellas. De modo que las personas no responden simplemente a estímulos o exteriorizan guiones culturales. Es el sentido subjetivo lo que dinamiza su acción, a través de un proceso de interpretación. Y la fenomenología busca conocer, precisamente, los significados que los individuos dan a su experiencia; lo importante es aprehender el proceso de interpretación por el que dichas personas definen su mundo y actúan en consecuencia.

\subsubsection{Definición de conceptos fundamentales}

Configuración subjetiva: categoría compleja que representa la unidad dinámica sobre la que se definen los diferentes sentidos subjetivos de los eventos sociales vividos por el hombre, dando cuenta de los significados de los acontecimientos (tanto objetivos como subjetivos) para los individuos que ocupan un determinado lugar en la estructura de la personalidad.

Dirección: actividad de planificar, organizar, liderar y controlar los procesos y recursos en la organización dirigida a alcanzar los objetivos es- tratégicos de esta. Actividad, por lo tanto, de carácter consciente y especializada, dirigida a guiar y orientar a las masas, trabajando con y a través de ellas, para el logro efectivo de dichos objetivos.

\section{Configuración subjetiva del ejer-} cicio de la dirección: nivel de integración superior de los sentidos psicológicos en función de una actividad concreta: dirigir. La persona en cuestión interpreta su lugar, función y habilidades por poner en práctica en el contexto de dicha actividad de un modo dinámico, procesal, incluso, circunstancial, no acabado, teniendo en cuenta la integración entre el pensar y el sentir del sujeto respecto al ejercicio de la dirección.

\subsubsection{Estudio de casos múltiples}

Esta investigación se sustenta en la estrategia metodológica estudio de casos y dentro de ella en el estudio de casos múltiples, que permite obtener de y con los sujetos todos los elementos necesarios para describir y caracterizar su subjetividad. Constituye una forma detallada de organizar y presentar la información, empleando varios casos que adquieren características únicas e irrepetibles en relación con el fenómeno de estudio.

Esta modalidad de estudio de casos se caracteriza por ser sistemática, 
holística y descriptiva; a partir de un proceso de indagación y examen detallado, se revelan conceptos y procesos que permiten analizar y comprender el ejercicio de la dirección de forma integral. Presenta además un carácter particularista, el cual determina que el estudio de caso se centre en la situación o fenómeno concreto. Permitiendo, esta peculiaridad, el análisis de problemas prácticos que surgen en la cotidianidad como los referidos a la actividad de dirección en la gerencia, así como la utilización de técnicas y procedimientos abiertos que posibiliten la recogida de información necesaria y el análisis de los datos, teniendo en cuenta las características de los sujetos por investigar.

\subsubsection{Criterios para la selección de los casos y descripción de los sujetos de investigación}

La presente investigación se desarrolló en el municipio Bayamo, provincia Granma, con dos mujeres dirigentes de la sucursal ARTex. Para la selección de los casos unidades de muestreo de esta investigación, se realizó un muestreo intencional opinático (Olabuénaga, 1999), pues en la selección emerge la intención de la investigadora mediante un criterio estratégico personal, orientado a la elección de aquellos sujetos dispuestos colaborar con el proceso y, además, que por su conocimiento de la situación o del problema por investigar pudieran brindar una información más rica de la problemática en cuestión. En relación a la cual, si de ejercicio de la dirección se trata, el sujeto que se desempeña en el cargo de gerente general es vital en este, así como su reserva de cuadros, pues la participación que tengan en la toma decisiones de la organización y, en consecuencia, de su curso es extensa; además de la posibilidad, que en relación con esto poseen, de legalizar el quehacer de la institución y contribuir a legitimarlo como válido.

\subsubsection{Técnicas y procedimientos utilizados}

- Análisis de documentos: se empleó con el propósito de obtener información previa y actualizada con respecto a las características de la entidad y las dificultades que ha presentado. Entre ellos se encuentran cartera de productos y servicios ARTex, trabajos de auditoría y resultados del estudio de clima organizacional.

- Observación no participante (ver anexo 1): permite obtener conocimientos acerca del comportamiento del objeto de estudio tal y como este se da en la realidad, siendo una manera de obtener la información directa e inmediata sobre el fenómeno que está siendo investigado. En 
este caso particular, con el objetivo de obtener información sobre la manifestación del ejercicio de la dirección por los sujetos investigados, a través de las expresiones verbales y no verbales emergidas en las situaciones acaecidas en cada sesión de trabajo. Al mismo tiempo, el rol de observadora pasiva favorece el reconocimiento de determinadas características identitarias presentes en tales manifestaciones y relacionadas con el ejercicio de la dirección.

- Entrevista en profundidad (ver anexo 2): con el objetivo de explorar la expresión de los indicadores diagnósticos definidos de configuración subjetiva del ejercicio de la dirección, que permitan su comprensión. Se realizará a través de una conversación entre el entrevistador y el entrevistado, donde se produzca un proceso de comunicación, permitiendo la empatía entre ambos. Se utilizan preguntas abiertas, brindándole importancia a los significados y sentidos expresados por estas mujeres de acuerdo con las vivencias y representaciones individuales.

La entrevista se desarrolló en tres sesiones de trabajo con el objetivo de explorar la expresión de indicadores diagnósticos definidos, tratando de mantener su carácter flexible, de conversación abierta y fluida. Dichas sesiones no se concibieron originalmente por indicadores, estos estuvieron dispersos en las preguntas formuladas de la entrevista, lo que favoreció la recogida de información respecto a cada uno.

Para desarrollar el análisis y procesamiento de los datos obtenidos durante los encuentros, con el objetivo de caracterizar el ejercicio de la dirección en la gerencia se utilizó el análisis de contenido, como procedimiento. Se tomó el contenido expresado por los sujetos en frases descriptivas que indicaban su relevancia para los objetivos trazados, pudiendo identificar las unidades de registro. Luego se hizo la interpretación de estas, permitiendo decodificar la información desde los referentes teóricos y la visión como investigadora; traducir sentimientos y explorar aspectos del mundo interior de los sujetos, que están poco concientizados y que en ocasiones entregan de manera poco clara. En la interpretación se tuvieron en cuenta además los silencios, las distorsiones y resistencias que pudo causar la entrevista, los que se señalaron para provocar una toma de conciencia e implicarla en el proceso de interpretación de sus propias vivencias. De esta manera se analizaron no solo los contenidos manifiestos, sino también los latentes. 
El trabajo estuvo validado a partir de la rigurosidad en el planteamiento del problema, de la coherencia entre el problema y el método por utilizar, así como de la emergencia de los sujetos de investigación en relación con lo anterior. Se realizó la triangulación como estrategia metodológica y vía de enriquecimiento del estudio por medio de la apertura a las vías de información, los modos de la interpretación y de control de calidad, y del contraste entre informaciones o interpretaciones coincidentes, lo mismo que discordantes (Olabuénaga, 1999). Empleándose la de datos, atendiendo a su diferenciación por haber sido recogidos $\mathrm{y}$ analizados en diferentes espacios, siendo vitales para la identificación del problema y la comprensión de este por los sujetos, además de teorías como apoyo a tal comprensión, funcionando como un todo en el proceso investigativo.

\section{RESULTADOS}

En la Gerencia ARTex, Sucursal Granma, el ejercicio de la dirección es configurado subjetivamente sobre la integración dinámica de sentidos que le confieren a esta actividad un valor instrumental o ganancial (en la búsqueda del estatus y poder correspondientes a esta, además del reconocimiento, prestigio y beneficios materiales a los que se puede acceder desde ella). Unido a un valor de compromiso moral, atendiendo al cumplimiento de las responsabilidades instituidas y a la ejecución de las funciones que lo caracterizan, las cuales deben conducir a la efectividad en el cumplimiento de la estrategia organizacional, a la que débilmente se integra, teniendo en cuenta su fuerza y autonomía en la regulación y autorregulación del comportamiento, la incorporación de esta actividad con un sentido de crecimiento y desarrollo personal, vivenciándose como contradictoria en el ambiente de la organización, donde no encuentra espacio para la realización.

Ello está transversalizado por los presupuestos, valores y principios legalizados y patentizados por la cultura organizacional durante la vida de la gerencia y subyacentes a la subjetividad grupal en el espacio de la institución, los cuales le imposibilitan unas veces y facilitan otras el ejercicio de la dirección. Esto revela el que se privilegie la dimensión económico-productiva en sus decisiones, conformación de la actividad laboral y cumplimiento de sus funciones, en detrimento de la satisfacción del factor humano, explicando el valor concedido a la organización de los medios, condiciones materiales y ambientales necesarias para la ejecución de la actividad laboral. No 
así del funcionamiento de la empresa y la toma de decisiones, atendiendo a los intereses y necesidades del colectivo laboral, que le permitan, a su vez, percibir a la sucursal como un espacio de prosperidad y participar de conjunto en su desarrollo, buscando una mayor integración y rentabilidad en la relación con el entorno.

Dato, además, integrante de una representación subjetiva, en la que, aun cuando existan una serie de conocimientos teóricos y prácticos válidos desde sus resultados, que le permitan poseer claridad de los objetivos, medios y utilidades de la actividad, concurra una discrepancia en el papel que va a desempeñar cada trabajador (desde lo que real y representativamente pueda hacer) en la obtención de la misión de la empresa que en sí los une a todos. Así como de la necesidad objetiva (no de concepciones estereotipadas o asumidas linealmente) de esta unión para obtener mejores resultados y una labor más satisfactoria para el colectivo, fragmentándose la representación generalizada de la actividad que desempeñan.

Subestimándose, además, el papel de dicho individuo en la contribución al desarrollo de la organización, así como de la capacidad que posea esta última para propiciar el crecimiento de este, a partir del grado de participación activa que el sujeto tenga en dicho proceso. Funcionando ello en la base de las debilidades afrontadas para la comunicación y trabajo en equipo presentadas por la gerencia.

Configurándose dinámicamente como un espacio donde se manifiesten valores de responsabilidad, solidaridad y compromiso, no existe una implicación profunda y compleja, desde su articulación, por parte de los sujetos que lo ejercen con el rumbo de la organización, lo que tiene como fuerza motriz esencialmente la satisfacción de necesidades básicas.

Integrándose a ello toda una regulación del comportamiento transversalizada por las concepciones y estereotipos de géneros, los cuales encuentran expresión en el espacio institucional, pues no existe discriminación para el cumplimiento de las funciones y exigencias del puesto de dirección, aunque dificulte su accionar, atendiendo a la perspectiva de los sujetos, por la sobrecarga de trabajo que vivencian en el cumplimiento de su doble jornada (en el trabajo y el hogar). Ubicándose ambas como mujer en defensa de su individualidad en un segundo plano, mostrando una orientación hacia los otros (generalmente hijos y pareja) y presentando, incluso, 
dificultades para identificar necesidades eintereses propios, alejados del bienestar de los demás. Elementos, que fusionados, han propiciado el deterioro de su salud.

Además de la presencia y el funcionamiento de una motivación marcada, en gran sentido, por las exigencias del medio, que integra en su base necesidades que no involucran los intereses de la organización. Tales necesidades se configuran en la relación dialéctica con el espacio organizacional, pero orientadas esencialmente hacia las directivas, empleando la gerencia como medio para obtener tales beneficios, e integrándose, además, a una satisfacción temporal básicamente inmediata.

Situación que explica el que a un individuo con una baja implicación con los resultados y futuro de su organización, incapaz, además, de visualizarla como una extensión de sus proyecciones internas, se le dificulte, como parte de la labor que ejecuta que es la dirección, la función de guiar, motivar y lograr un objetivo trabajando con y a través de los trabajadores como potencial humano más que como recurso.

Todo esto marca una distancia entre la dirección y restantes factores de la organización, rompiendo diametralmente las expectativas de los demás trabajadores de la gerencia con sus dirigentes. En función de esto se debilita la identificación con el cumplimiento eficiente de la misión social como sentimiento colectivo y se limita al cumplimiento del factor económico-productivo para sobrellevar el presente. Razón por lo que la configuración subjetiva del ejercicio de la dirección en estas dirigentes se construye dinámicamente de forma regresiva, faltando creatividad en la incursión de nuevas y arriesgadas soluciones, así como de la posibilidad de implementar cambios necesarios. Sin embargo, exhiben una capacidad de reflexión y crítica, que, si bien les permite identificar problemáticas y recursos, no moviliza sus comportamientos hacia la búsqueda de las soluciones, erigiéndose, entonces, como recursos útiles para el futuro tratamiento de las dificultades asociadas a ello.

\section{CONCLUSIONES}

1. Resultaron definidos como indicadores diagnósticos de la configuración subjetiva del ejercicio de la dirección en directivos los siguientes: representación subjetiva, vivencias, motivación, sentido subjetivo y dinámica de la configuración subjetiva del ejercicio de la dirección.

2. El estado actual de la configuración subjetiva se caracteriza por: 
- Representaciones subjetivas del ejercicio de la dirección construidas en niveles de dirección diferentes por los sujetos, que tienen como base tanto el conocimiento teórico como el práctico de la actividad de dirección y están mediadas por el rol que desempeñan en la empresa.

- Un potencial motivacional basado en necesidades básicas de inmediatez en su satisfacción configuradas en motivos con una débil integración, emergiendo los motivos presentes ante condiciones actuantes y los orientadores de la actividad y las relaciones humanas.

- La emergencia de sentidos de cumplimiento del deber integrados al interés ganancial, como ejes dinamizadores de la configuración subjetiva del ejercicio de la dirección de los sujetos.

- Presencia de una dinámica configuracional esencialmente regresiva, que denota una capacidad para identificar las problemáticas presentes y su jerarquización, dificultándole su proyección mediata y organización en función de lo 'importante', unido a la optimización de los recursos para garantizar las soluciones futuras más eficientes.

\section{REFERENCIAS}

Bisquerra, R. (1989). Metodología cualitativa. Barcelona: CEAC. Material en soporte magnético.

Blanco Colunga, C. J. (s. f.). Sentidos personales: indicadores para su estudio. Recuperado del sitio web del Departamento de Psicología, Facultad de Ciencias Sociales, Universidad de Oriente, Santiago de Cuba.

Calviño Valdéz-Fauly, M. (2000). Temas de psicología y marxismo: tramas y subtramas. La Habana: Editorial Félix Varela.

Calviño Valdéz-Fauly, M. (2002). Análisis dinámico del comportamiento. La Habana: Editorial Félix Varela.

Cordero Leyva, I. A. (2009). Configuración subjetiva de los valores organizacionales compartidos como herramienta de la dirección estratégica (Tesis para optar al título de Psicóloga, Facultad de Ciencias Sociales, Universidad de Oriente, Santiago de Cuba, Cuba).

Delgado Hernández, H. (2011). Una aproximación al desarrollo subjetivo de la motivación (Tesis para optar al título de Licenciado en Psicología, Facultad de Ciencias Sociales, Universidad de Oriente, Santiago de Cuba, Cuba). 
Domínguez Carrazco, M., Maceo Vargas, D., \& Fonseca Pérez, I. (2009). Sentido personal del rol de dirigentes en mujeres directivas. Trabajo de final de la asignatura Aspectos Metodológicos e Investigativos 3 y 4, Facultad de Ciencias Sociales, Departamento de Psicología, Universidad de Oriente, Santiago de Cuba.

Fernández, L.M.(s. f.). Instituciones educativas. Dinámicas institucionales en situaciones críticas. Buenos Aires: Editorial Paidós.

Fernández Rius, L. (2002). Pensando en la personalidad. Personalidad. Algunos presupuestos para su estudio. La Habana: Editorial Félix Varela.

González Rey, F. (1983/1987). Motivación profesional en adolescentes y jóvenes. La Habana: Editorial Pueblo y Educación.

González Rey, F. (1997). Epistemología cualitativa y subjetividad. La Habana: Editorial Pueblo y Educación. [Versión digital].

González Rey, F., \& Mitjáns Martínez, A. (1990). La personalidad, su educación y desarrollo. La Habana: Editorial Pueblo y Educación.

González de la Rosa, P. (2010). Autonomía en mujeres directivas. Un estudio de casos múltiple (Tesis para optar al título de Psicóloga, Facultad de Ciencias Sociales, Universidad de Oriente, Santiago de Cuba).
González Serra, D. J. (1995/2001). Teoría de la motivación y práctica profesional. La Habana: Editorial Pueblo y Educación.

Leontiev, A. N. (1974/1983). Actividad, conciencia y personalidad. La Habana: Editorial Pueblo y Educación.

LópezMustelier, R.(2011). Resumen de conferencias de la asignatura Psicología de las Organizaciones. [Versión digital].

Manzano Vidal, N. (2010). Un acercamiento a la configuración subjetiva de la capacitación de la auxiliares generales del hogar infantil (Tesis para optar al título de Psicólogo, Facultad de Ciencias Sociales, Universidad de Oriente, Santiago de Cuba).

Núñez de Villavicencio, F. (2000). Psicología de la salud. La Habana: Editorial Ciencias Médicas.

Ramayo Canon, R., \& Rodríguez Laffita, Y. (2002). Configuración subjetiva del ejercicio de la dirección (Tesis para optar por el título de Psicóloga, Facultad de Ciencias Sociales, Universidad de Oriente, Santiago de Cuba).

Reyes Ferrer, B. E. (2011). Percepción de la dirección administrativa en la Dirección Municipal de Salud de San Luis (Tesis para optar por el título de Psicóloga, Facultad de Ciencias Sociales, Universidad de Oriente, Santiago de Cuba). 
Riquenes Suárez, L. (2009). Estudio de la motivación del intento de emigración ilegal por penetración a la base naval (Tesis para optar al título de Psicóloga, Facultad de Ciencias Sociales, Universidad de Oriente, Santiago de Cuba).

Rodríguez, G., Gil, J., \& García, E. (1996). Metodología de investigación cualitativa. La Habana: Editorial Félix Varela.
Rubinstein, L. J. (1940/1982). Principios de psicología general. La Habana: Editorial Pueblo y Educación.

Vigotsky, L. S. (1933). Obras escogidas. IV. Psicología infantil. Parte II. La crisis de los siete años. Academia de Ciencias Pedagógicas de la URSs. [Versión digital]. Zaldívar Pérez, D. F. (1999). Psicoterapia y orientación histórico-cultural. Revista Cubana de Psicología, 3(16), 165-168. 